\title{
The Learning Space as Support to Sustainable Development: A Revision of Uses and Design Processes
}

\author{
Sergio Alonso Martínez-Ramos ${ }^{+}\left(\mathbb{D}\right.$, Juvenal Rodríguez-Reséndiz *,+(i), Avatar Flores Gutiérrez ${ }^{+}(\mathbb{D}$, \\ P. Y. Sevilla-Camacho ${ }^{+}(\mathbb{D})$ and Jorge D. Mendiola-Santíbañez (i)
}

Facultad de Ingeniería, Universidad Autónoma de Querétaro, Querétaro 76010, Mexico; sergio.martinez@uaq.mx (S.A.M.-R.); avatar.flores@uaq.mx (A.F.G.); psevilla@upchiapas.edu.mx (P.Y.S.-C.); mendijor@uaq.mx (J.D.M.-S.)

* Correspondence: juvenal@uaq.edu.mx; Tel.: +52-442-192-12-00

+ These authors contributed equally to this work.

check for updates

Citation: Martínez-Ramos, S.A.; Rodríguez-Reséndiz, J.; Gutiérrez, A.F.; Sevilla-Camacho, P.Y.; Mendiola-Santíbañez, J.D. The Learning Space as Support to Sustainable Development: A Revision of Uses and Design Processes. Sustainability 2021, 13, 11609. https://doi.org/10.3390/su132111609

Academic Editors: José Antonio Marín-Marín, Margarita Pino-Juste, Jesús López Belmonte and Antonio José Moreno Guerrero

Received: 10 September 2021

Accepted: 14 October 2021

Published: 20 October 2021

Publisher's Note: MDPI stays neutral with regard to jurisdictional claims in published maps and institutional affiliations.

Copyright: (c) 2021 by the authors. Licensee MDPI, Basel, Switzerland. This article is an open access article distributed under the terms and conditions of the Creative Commons Attribution (CC BY) license (https:/ / creativecommons.org/licenses/by/ $4.0 /)$.

\begin{abstract}
In the last decade, there has been an increasing interest in the role of space in the learning process. However, there is limited research about how different Learning Spaces (LS) can lead to Sustainable Development (SD). Therefore, this paper presents a systematic literature review aimed to identify how physical, virtual, and hybrid LS have been designed and used to support SD. From an initial sample of 204 articles between 2009 and 2021 found in the Scopus database, 33 were included after inclusion criteria were applied. Findings show a wide variety of focus in the uses of LS (e.g., promote education quality, accessibility, or environmental sustainability). In general, the design process of LS implies a top-bottom approach, where students remain as passive actors. Nevertheless, it has been identified a growing interest in codesign processes that promote broader participation and bottom-top perspectives. This study contributes to orientate the understanding of the concept of LS, and looks towards inspiring new teaching and learning practices.
\end{abstract}

Keywords: learning space; sustainability; sustainable development; design; literature review

\section{Introduction}

During the COVID-19 pandemic, education sector has been disrupted. Around 94\% of worldwide students were affected by required mandatory close-downs of schools and other learning spaces [1]. During this period, homes became the main space where physical and digital elements converged to support education [2]. Through this crisis, in the public debate has been observed a rush for trying to get back to normal [3]. Contrarily, critical voices alert about the risk of returning as before (if it is even possible). Therefore, it is proposed to use this moment as an opportunity to re-orientate education systems towards Sustainable Development (SD) [4].

Three dimensions must be balanced and integrated to archive SD: social, environmental, and economic [5]. In this process, education plays a significant role in supporting the transition. However, the institutional activities directed to SD, have been limited to integrating sustainability concepts in their curriculum and offering specialty courses for careers in related fields. These activities are helpful but not enough to promote behavior and attitudinal changes [6]. Then, it is proposed to create interactive and learner-centered spaces [7]. This requires holistic approaches to address the different aspects of learning environments, refered to the diverse locations, contexts, and cultures in which students learn $[8,9]$. The research of learning environments initially was focused on psychological and social factors. Lately, there has been a growing focus on the role of spatial and physical elements involved in the learning process. This area is conceived as the study of Learning Spaces (LS) [10].

Empirical evidence shows that LS have a significant effect on learning outcomes. For example, it has been studied how the morphological composition of a physical environment 
can support six learning theories (behaviorism, cognitivism, constructivism, experiential, humanistic, and social-situational) [11]. Nevertheless, studies that explore how learning spaces are designed and used to archive specific learning outcomes are limited [12]. There is not a simple answer about how to design them, but there is an increasing interest in establishing principles for it [13].

Traditionally, LS refers to school-built spaces [14]. Regardless, it has been recognized that all areas occupied by humans at every scale can become LS [15]. Then LS may include outside-of-school locations, outdoor places, and work settings expanded with learning features [16]. Additionally, concepts as digital learning environments have been growing along with the integration of education with information and communication technologies (ICT). By recognizing the fast-changing context of the twenty century, advanced technologies have been proposed to enhance the learning experience. Examples include the internet of things, artificial intelligence, big data, augmented/virtual reality, and blockchain [11]. Then, it is considered that learning in 2021 occurs in multiple physical and digital spaces, at different times, and following a diversity of means and methods [17].

Some literature reviews education for SD, focusing on analyzing the main themes in this field [18], the conceptualization and operationalization of concepts [19], and the evaluation process of educational buildings and learning environments [10]. However, it has been identified that studies focused on the design and use of LS to support and promote SD are limited. Therefore, this work presents a systematic review of literature to identify case studies towards response the following research questions:

RQ1. How have LS been used to support SD?

RQ2. How LS that supports SD have been designed?

This paper starts by offering a description of the main concepts of the review in Section 1.1.1. Then, the methodology used based on the PRISMA 2020 checklist is presented in Section 2. Main findings and insights that provide a general overview of cases where LS have supported SD are presented in Section 3. Reflections, recommendations, and further research topics are discussed in Section 4. Finally, Section 5 offers the conclusions of the authors.

\subsection{Main Concepts}

\subsubsection{Learning Space}

Among the different perspectives that seek to study and describe the phenomenon of learning, one of them considers that the key factor for its study is to observe it in context. Situated learning proposes that this phenomenon manifests itself as the result of the interactions of the student and a vast constellation of factors that transcend individual cognitive processes. One such factor is the place where it occurs [20]. These places can be studied from a socio-material perspective and described as learning environments, where space is one of its constituent elements [21].

The term space can refer to a time-lapse or to where matter is located and contained [22]. In this work we focus on the second one. From a physical perspective, space is where matter is located and contained. It can be described as a relatively objective three-dimensional extension of reality, defined by the contours of natural or architectural structures and locations [23]. In an abstract form, the matter is substituted by substantive items. This approach is helpful to describe the digital, cyber and/or virtual space phenomenon that is seen as an alternative and not as a copy of the physical space [24,25]. Access to digital spaces relies on a physical object (e.g., digital device screen) powered by information and communication technologies (ICT). Therefore, the study of digital spaces may include physical artifacts [26].

\subsubsection{Education and SD}

The base foundations of the idea of sustainability and sustainable development can be identified since the first civilizations, gaining particular relevance in the XX century [27]. This is reflected in the actions of academics, activists, and international organizations as 
the United Nations towards promoting it globally. Although its consecution is considered a wicked problem, there have been efforts to establish a common ground for its study and oriented practice [28]. One of them is the development of the 2030 agenda, which includes 17 focus areas and 169 specific targets. This document offers a general strategy and proposes actions to tackle the global challenges to benefit current and future generations [29]. For this study, it is considered that this plan is helpful to operationalize the complexity of the SD concept.

For SD, education is considered a goal and a mean at the same time. Therefore, it is regarded as one of the critical factors for SD [30]. The 2030 Agenda proposed by the United Nations presents 17 Sustainable Development Goals (SDGs). Objective number 4, called Quality Education, seeks to promote access to quality education inclusively, focusing on increasing the number of students at different educational levels [31]. However, not all education is considered to support SD. For this reason, the Education for Sustainable Development (ESD) approach has been proposed. In this case, the objective is empowering people to make informed and responsible decisions, where people are part of the process of seeking sustainability. For this, the development and assessment of competencies have been proposed (e.g., anticipation, collaboration, systemic thinking, critical thinking) [32].

\subsubsection{Design for SD}

In order to archive SD, there is a need to transform strategies into actions [33]. This implies a conscious take decision process to develop experiments and interventions to materialize creativity) [34]. Modern design looks to specialize in applying knowledge from all specialized fields, combining technologies with human efforts to transform the world [35]. Social design and transitions design has been focusing on offering methods and tools to the consecution of sustainable development [36]. These perspectives are characterized by collaborative and holistic approaches to changing current into desirable situations by developing products, services, processes, systems and spaces [37]. In the educational context, the LS design specializes in the systematic analysis, planning, development, implementation, and evaluation of settings where learning takes place [17]. Therefore, it is considered relevant to identify formal and not-design processes in this field that promotes SD.

\section{Methods}

This literature review followed the recommendations proposed in the Preferred Reporting Items for Systematic Reviews and Meta-Analyses (PRISMA) checklist. The keywords selected and used to create search strings were: learning space, sustainable, sustainability, design, process, and framework. The search included scientific articles, conference papers, and academic book chapters in English, which was conducted among the title, abstract, and keywords. The search was conducted on 1 May 2021, limiting to publications between 2009 and 2021 found in the Scopus electronic database. These years were selected by using the date that $4 \mathrm{G}$ networks started to operate as the time reference point. This event has been considered relevant into the diffusion of the web 2.0 or social web. After excluding duplicates, the initial sample resulted in 209 works. Then a screening and coding process was conducted to categorize the documents. By reading abstracts and full texts, a final sample was selected, excluding papers that do not contain explicitly concepts related to:

- $\quad$ SD Goals (e.g., quality education);

- $\quad$ ESD competencies (e.g., problem-solving);

- $\quad$ Physical/digital/hybrid spaces.

Inductive qualitative content analysis was used to code and categorize the items. Information about the characteristics of LS, SD focus, and design process was extracted from each work. The final sample resulted in thirty-three articles included in the review. The PRISMA flowchart that was followed in this study is presented in Figure 1. 


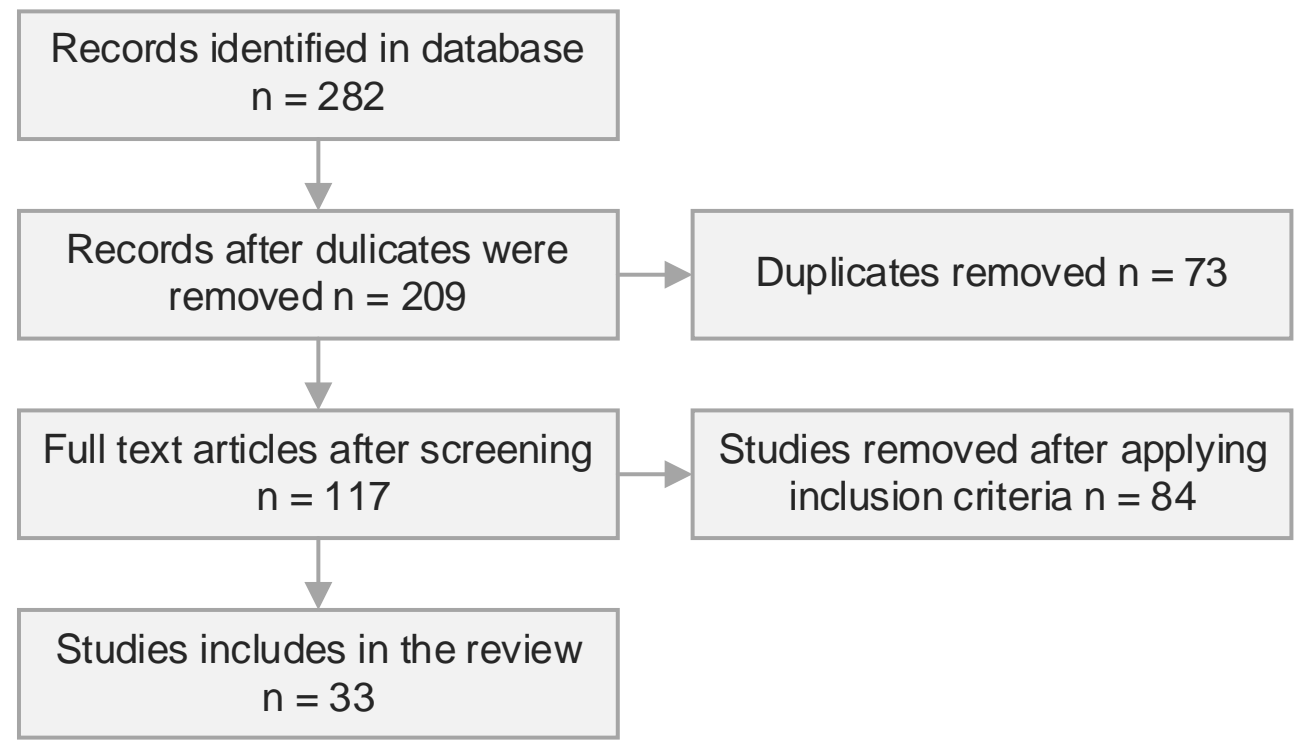

Figure 1. Systematic review flowchart for this work.

\section{Findings}

Final sample included 33 articles (80\%), 5 book chapters $(16.7 \%), 2$ reviews $(6.7 \%)$ and 2 conference papers $(6.7 \%)$. The disciplinary focus of the documents included education $(42.4 \%)$, environmental sciences $(33.0 \%)$, social sciences $(15.2 \%)$, engineering $(6.1 \%)$, multidisciplinary (3.0\%). From a bibliometric perspective, it is observed that after 2017 the number of studies that include the LS and SD concepts has grown substantially. However, as Figure 2 shows, the number of studies included in this review remained relatively low for the screened sample. This is attributed to vague descriptions of concepts as space and sustainability in some of the studies reviewed.

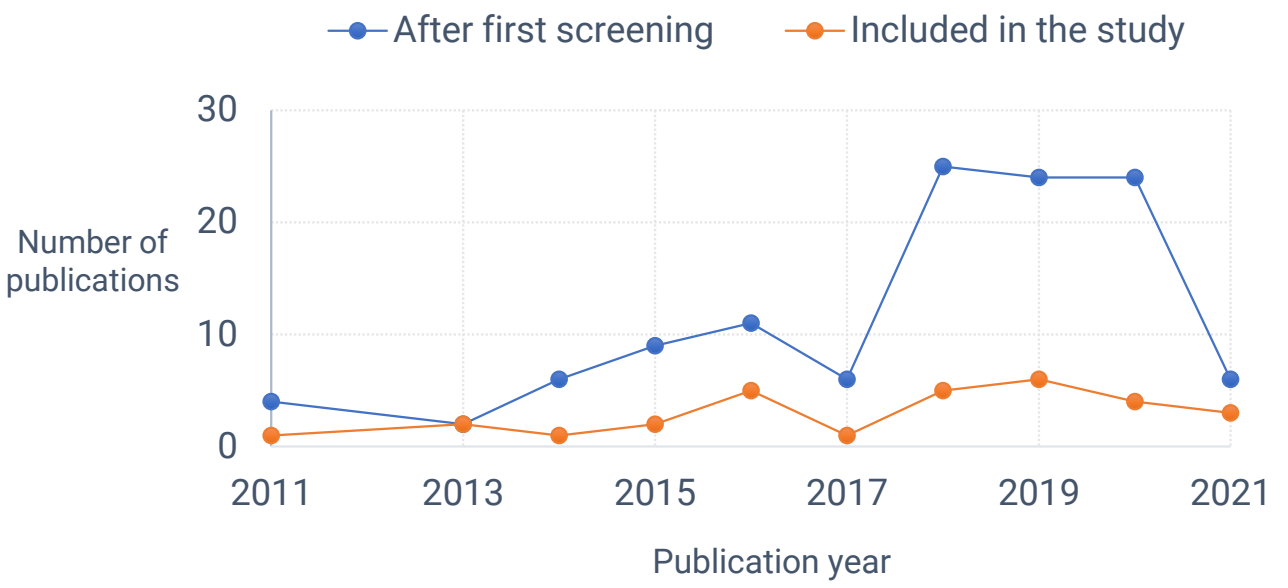

Figure 2. Number of studies by year.

\subsection{Learning Space}

\subsubsection{Physical Space}

In the revision it has been identified a growing interest in the relations between characteristics of physic space and learning (Table 1). The majority of the works found were published between 2019 and 2021. Thirteen studies were selected in this category, representing $38 \%$ of the final sample. Table 1 shows the main findings. 
Table 1. Physical spaces that are used to promote SD and its focus.

\begin{tabular}{cc}
\hline Variable & Representation \\
\hline City & Sustainable transitions Environmental sustainability \\
Campus & Accessibility to persons with disabilities \\
Buildings & Acoustic conditions/Education quality \\
House & Energy/Housing/Environmental sustainability \\
Outdoor & Environmental sustainability \\
Classrooms & Lifelong learning/Peace/Education quality \\
Workshops & Education for work/ESD competencies \\
Furniture & Acoustic conditions/Education quality \\
Staffroom & Innovation and collaboration \\
\hline
\end{tabular}

The broader topic in this area is related to how the characteristics of the buildings can influence the learning experience. Acoustic comfort is considered as a factor to facilitate innovation that helps in progress towards SDGs. A series of recommendations in order to improve the acoustic conditions of LS are mentioned. These ranged from special furniture, the use of impact-absorbing materials in interiors, and the design of new geometries of space [38]. Under a similar approach, academic performance and physical space perception of classrooms have been correlated. There, ventilation was found as a significant influence on academic performance, encouraging further research in the relation of space and learning from a holistic approach [39]. Another study explores open-air buildings and their relation with thermal and visual comfort, health, wellbeing, and energy consumption. There, good and bad practices are proposed to reduce energy and maintenance costs, prevent health disorders, and supporting the learning process [40].

In order to study the relationship between space with math and arts education, an Indoor Physical Environment Perception scale is used to assess classroom characteristics and classifying them into three categories: workspace comfort, natural environment, and building environment [41]. The importance of the physical, material, and aesthetics conditions of schools is emphasized, concluding that the design of learning spaces can support or be a barrier to the learning process. In other cases, spaces may be incoherent with sustainability practices, recommending further research to explore the daily aesthetics of learning spaces [42].

The design of schools is another recurrent topic. There, the importance of collaboration between multiple stakeholders is highlighted, especially to create a sustainable campus model [43]. In this area, it is recommended to include students with disabilities in the design process related to different elements of the campus. This group finds physical barriers in infrastructure and space as one of the main difficulties in their learning process [44].

Two cases shows specific learning spaces created with a focus to promote ESD and SDGs. First, a study case focused on industrial engineering education. There, in a wood workshop, the student studied and applied lean manufacturing concepts by simulating different role positions (e.g., operator, supervisor, inspector, manager). This led to the development of knowledge and competencies required in the job market [45]. Second, a proposal was found to design-build a tiny house to generate an experiential learning space. This context served to learn about issues related to energy, housing, and the environment. The proposal includes the active participation of students from structural analysis, sustainable design, architecture, and energy utilization courses [46].

An interesting research area was found in the use of spaces to promote the development of community and networks. For example, the exploration of the everyday activity of commensality (coming together around a table to eat) as a form to promote lifelong and intergenerational learning opportunities. Bring food to share sessions were held in classrooms where the students could do life with one another. In this context, the use of smartphones was questioned and discussed as an obstruction to social connectivity [47]. Under a similar approach, the staffroom is considered as a professional learning space, describing how these can serve as a hub to develop communities that promote SD [48]. 
Finally, some cases that describe the use of outdoor and out-of-school spaces to develop learning processes were found. For example, in order to teach science topics (chemistry, biology, physics, and math), a learning experience that involved going outside the classrooms and find water sources in the surroundings of schools was developed. There, students explored ideas about water treatment and the role of homeowners in the communities. Results showed a positive enjoyment and engagement of students [49]. Additionally, it was found how some universities promote regional sustainable transitions by conducting activities in spaces outside their campuses. The activities included a range of methods that involved expert talks, hands-on work, excursions, interviews, city walks, label rallies, visits, surveys, mappings, and games. The spaces that hosted these activities included stores, gardens, agriculture fields, newspaper offices, parks, start-ups, community housing projects, libraries, and festivals. The activities were received positively by the students, teachers, and regional partners. However, it implied additional administrative and organizational difficulties, ranging from insurances, entrance fees, transport, extra payment for teachers, and questions from authorities [50].

\subsubsection{Digital Learning Space}

This alternative to physical space offers the possibility to navigate between multiple scales of spaces that promotes a variety of sustainability focus (Table 2). However, it was found that the access barriers to these spaces are a general concern in this research.

Table 2. Main digital spaces found in this study and its sustainability focus.

\begin{tabular}{cc}
\hline Space Used & SD and ESD Focus \\
\hline Apps & ESD/Problem solving \\
Facebook & Social inclusion and accessibility \\
Online platforms & ESD/Collaboration \\
Digital campus & Lifelong learning/Problem solving \\
Virtual university & Lifelong learning/Accessibility \\
\hline
\end{tabular}

It is considered that in order to access a digital LS, there is a need for a physical artifact, being the first element of that space. Following this perspective, a study case shows how Ipads were used to promote the problem-solving skills of students. Despite its popularity in schools, professors have found the Apple ecosystem locks as a barrier to implementing new teaching strategies. Storage capacity was an issue that caused significant problems when software upgrades, apps, and student work start to fill up. Additionally, a lack of technical knowledge was a fundamental challenge to solve in developing this educational program [51].

Access to hardware does not guarantee access to digital spaces. A study exploring the challenges of offering quality education to students with visual impairments during the COVID-19 pandemic found that the most crucial factor for students was access to internet data, which in most cases implied a cost for the students [52]. A solution to this challenge is proposed in the use of Facebook as a digital LS for indigenous students, instead of learning management systems traditionally used by universities to provide content (e.g., Moodle, Blackboard). Additionally to the familiarity with the interface and the social activity of Facebook, an important factor of the positive feedback was the fact this platform is part of their mobile plan [53].

Then, the range and characteristics of digital spaces available are a recurrent topic in this category. To support collaboration within and between communities to accelerate sustainable community development efforts, a specific digital LS was designed. This online platform offers meeting rooms, online boards, a forum, and a private library [54]. A similar approach was found in a digital LS designed for self-directed and team-based learning challenges. Here, the intention was to get an unobtrusive data collection of users in order to improve educational programs [55]. 
From a meso level, the concept of virtual university was identified. There, it is recognized the utility to study online courses from a learning environment perspective, referring to putting learning as the primary purpose and direction of it. However, it is proposed to explore the concept of virtual space going beyond simple online courses. This means that students could move, explore, experiment, have serendipity moments, make choices about this space, and then turn it into a place with cultural significance (e.g., protests, commerce, celebrations). As a result, this could facilitate lifelong learning and problem-solving thinking [56].

Finally, from a macro perspective, a research work shows how to promote the incorporation of ICT in education in a country. This case study presents how ICT-based public services have been created to support life-long learning. The objective of this strategy is to cover $100 \%$ of schools by digital campuses. This intends that anyone can learn anywhere at any time. By the end of June of 2021, a National Education Resource Public Service Platform in China had connected to 65 online platforms, having 12 million access to online learning courses, and reaching 3.37 million active users [57].

\subsubsection{Hybrid Space}

This work identified cases where the LS is proposed as a combination of physical and digital elements but where their distinctions are recognized (Table 3). Therefore these LS are considered hybrid spaces [58].

Table 3. Hybrid spaces found in this study, the tools used, and their sustainability focus.

\begin{tabular}{|c|c|c|}
\hline Hybrid Space & Technology & Focus \\
\hline Classroom/Video conferencing platform & $\begin{array}{c}\text { Interactive screens, camera, tables, } \\
\text { sound equipment }\end{array}$ & Education quality \\
\hline Campus/Online resources & Classroom/Digital repository & Education for sustainable development \\
\hline Campus/Technology-enhanced space & Smartphone/Augmented reality & Environment sustainability \\
\hline
\end{tabular}

During the pandemic period, challenges related to the digital divide have been evident. In this context, it is considered that to keep offering quality education, there is a need to integrate multiple physical and digital elements to create LS that respond to local contexts [59].

In the new normal, traditional teaching and learning have been a challenge, especially where the attendance to the physical classroom is voluntary. In this context, one of the main complaints of teachers is that, in order to support students that attend physical and digital spaces, they now have to teach the same course twice. In this context, an online-mergeoffline learning mode is presented. There, teachers and some students are physically in a classroom. Meanwhile, the rest of the students access remotely to the classroom by the use of interactive screens, cameras, tablets, and sound equipment. The pilot implementation of this model resulted in positive perceptions from teachers and students [60]. This is an example of how hybrid spaces can be understood. In this context, physical and digital LS merge, but it is possible to differentiate them for its study.

A case study shows how to provide tools for embedding sustainability in teaching activities outside the pandemic context. As a part of a postgraduate certificate in academic practice, a module of ESD was developed and implemented in two iterations. The first one was conducted just in a classroom using a traditional higher education pedagogy. Focusing on implementing ESD philosophical principles, the second one included study activities in a digital space. Then, there were campus tours involving stairwells, boiler rooms, recycling/waste facilities, kitchens, coffee shops, and parks. Participants showed positive feedback regarding satisfaction, engagement, and perceived contribution to professional development [61].

Another case recognizes the difference between physical and digital elements. There was found an exploration in the use of iPads against the use of laptops to improve the performance of students inside classrooms. There, the public and private workspace concepts 
are presented, associated with personal and collaborative work. Results show that tablets are more helpful to support student-to-student interactions, improve communication, and triggering co-ideation processes [62].

Finally, it was found the use of the concept of enhanced physical space for reviewing the use of Bluetooth beacons. This technology can be used from attendance monitoring, energy-saving detection systems, offer specific information that promotes recycling activities, and stimulate learning by Augmented reality systems [63].

\subsection{Design Process}

In general, the case studies found do not mention the design process of the LS presented. However, it was found that generally, it was followed a top-down approach. Under this perspective, initially, governments and education organizations are responsible for the design process. After formulating strategies, it relies on the teacher and its practice to use or find new uses of space.

On a micro-scale, it was identified the classroom layouts as an active element in the learning process. These are usually organized by the teacher, anticipating the needs of the students. However, the difference between students implies that there is a constant negotiation between teachers and students. This reflects the importance of including the students and other actors in the design process, complementing top-down strategies with bottom-up initiatives [64]. This perspective was found in the discussion of the results of an initiative to promote innovative teaching and learning practices, observing that new bottom-up initiatives are constantly emerging. However, these rely on the support of top-down strategies to achieve success [65]. Following this perspective, a process where schools transformed traditional classroom arrangements into flexible learning spaces is presented. From interviews, discussions, brainstorming, and rapid prototyping, different actors were considered to envision a new LS. In this process, the integration of students, teachers, and the community was regarded as the key factor to success. Therefore, it is recommended to use collaborative end-user-centered perspectives instead of top-down approaches [66].

Under the approach to broaden the inclusion of different categories of actors, a Designbased research framework was used to develop sustainable online learning spaces for children with diabetes. In this process, the participation of young people (aged between 11-13), parents, and clinicians were considered fundamental for the project [67]. Additionally, there is an interesting case where a physical transition to a new university building was the catalyst for a reimagining of the teaching practice. This was followed by the design and implementation of a professional development program that looked towards next-generation learning spaces. The design process involved understanding the learning space design and creating the vision of an ideal learning environment from the faculty stakeholders. This vision resulted from a consultation period, where the faculty perceptions of room layouts were an essential element of the process. Additionally, a replica of a learning space was used to facilitate the modeling of teaching practices. Their outcomes assessment of the behavioral attitudinal change in the faculty members showed an increase in the work and collaborative learning, where the layouts of classrooms supported the teaching and learning practice [68].

Insights obtained from a LS codesign project proposes 4 phases: codesign activities, student exhibition and feedback, professional design evaluation, and final satisfaction evaluation survey [69]. A codesign and research-through design approach are also used to design a board game focused on promoting energy topics discussion [70]. A relevant insight found in this case study is that the ambiguity and inconclusiveness of the rules were helpful to evoke group discussions and trigger learning experiences.

After a visit to Finland schools, some professors engaged in collaborative practices to seeding new learning experiences. By applying design thinking principles in the development of an outdoor learning experience, the voice of the most dissatisfied group of students was used to get insights about how to motivate students learning and development [50]. 
Codesign process that involves universities, teachers, and regional partners can be a key factor to the success of the course. This implies extra time and effort. Therefore, it is recommended to address this challenge by the development of networks between science and society. Here, empathy and trust are presented as crucial for teaching cooperation [51].

From a research and diagnosis perspective, the use of an Activity Centered Analysis and Design framework is proposed. In this work, an online survey was conducted to collect quantitative and qualitative data about technologies, material artifacts, and physical spaces of schools. Conclusion refers to the importance of the study of the physical, conceptual, and social structures to support educators towards transitions to new teaching practices that respond to contemporary times [71].

\section{Discussion}

\subsection{Conceptual Analysis}

This review found that the use of LS in some cases refers to a broader perspective that does not designates physical, hybrid, or digital spaces. For example, the use of inbetween LS for sustainability learning to describe transdisciplinary research and learning activities [72]. Another example is the use of the concept of LS to describe specific moments where students and staff engage in learning activities [73]. A similar use is identified conferences, forums, workshops, and similar events are proposed as LS to promote climate change learning. In these cases, it looks that the LS concept is used as a synonym of learning environment [74].

The use of LS as an abstract object is common. Under this perspective, the physical space often is not described, ignored, or simply forgotten. This is a sign of the lack of understanding about how space can affect the learning experience. An interesting comment that reflects this emerges from a participant of a Fellowship program described as a transformative LS. The experience was described as mentally and physically stretching. However, the study does not mention any characteristics of the physical conditions of the space where the intensive mental work was healed [47]. Despite the multiple possible interpretations of the term LS, it seems to be useful to establish conceptual differences to describe and understand the learning phenomenon. Therefore, this work proposes understanding the LS as part of a learning environment and three main categories for its study: physical, hybrid, and digital.

A substantial part of the literature reviewed shows a constant intention to improve the quality of education and promote sustainable practices. However, in a vast number of works, there is no description of how the concept of sustainability is interpreted or how to assess the impact of interventions on it. Therefore, in some cases, it remains a vague objective or just as a buzzword. Thus, it is considered that the SDGs targets and ESD competencies are useful to operationalize the complexity of the sustainability concept and to describe its relationship with the educational phenomena.

\subsection{The Use of Physical, Digital and Hybrid LS}

In physical LS, the layout configuration plays an essential role in the learning process. In a large room with a heterogeneous sound quality, access to front rows can be a differential factor during lectures. In some cases, professors have meaningful interactions with students in front rows. Something similar occurred in the digital space. It has been observed that the physical size of the display may have a significant impact on how digital space is accessed and perceived.

There exist major differences in the physical space between the screen of a smartphone, a laptop, a monitor, a digital blackboard, or even bigger screens. Therefore, challenges associated with physical LS could emerge in digital setups. For example, in videoconference (e.g., Zoom, Google Classroom) and board platforms (e.g., Trello, Padlet), the size of the screen limits the number of active cameras or boards that can be seen at the same time. Consequently, it is recommended to include the physical characteristics of the devices in the description of digital LS. 
In hybrid and digital spaces, hardware requirements go beyond the budget of students. This can be supported by laboratories and programs to reduce the cost of hardware. Additionally, private software and platforms may limit access. Then, it seems that there is a need for open-source solutions and guarantees for free access to the internet to promote education and SD.

\subsection{Design and Policies Opportunities}

The characteristics of physical LS affect the learning experience, impacting the quality of education and the development of competencies for SD. Therefore, their design is a concern for the education practice and research. In schools where students use an only classroom for an extended period, the space can be constantly adapted to different goals. However, classrooms are usually used for diverse courses that do not always share their learning objectives and pedagogies in higher education. This means that classrooms will maintain the same layout ignoring the needs of the specific needs of the courses. A simple solution is using mobile furniture, but offering flexible spaces and allowing the use of multiple spaces could trigger innovative teaching practices.

The physical space should be designed collectively. In the process, there are many examples of spaces that can be used as referents to generate ideas about how to generate new spaces, from campus to furniture. In contrast, the existence of digital space is relatively new. Additionally, the lack of technical knowledge could be a barrier to generate new ideas about how digital space may be designed and used. This can impact the teaching and learning process, affecting the development of ESD competencies.

It was found that new teaching practices promote experiential learning. Disciplines that usually have hands-on activities (e.g., engineering, architecture, medicine) present opportunities to use multiple spaces out-of-classrooms (e.g., workshops, laboratories, the campus, and the city). Additionally, these disciplines usually integrate SDGs and ESD concepts in their curriculum. However, there are few cases of the use of spaces to promote $\mathrm{SD}$ in fields such as law, finances, or management. This is reflected in the disciplines represented in the sample. Therefore, it is considered that there is an opportunity to develop new teaching for those branches of knowledge.

An insight obtained in this research is the profound interest in generating a positive impact on the students. Nevertheless, there is a recurrent call for supporting the professors in this process. There are comments of students who considered that teachers are not always prepared to offer new teaching practices involving technology [65]. This implies the need for more training and professor development. There is a significant opportunity to create spaces for professors learning. This is a relevant topic for research because professors usually have the primary responsibility for establishing how the LS are used.In some cases, professors prefer to consult colleagues instead of access to development programs based on traditional pedagogies. Additionally, there is a need for education on SD and ESD competencies to be integrated into the teaching practices. Finally, there is a recurring concern about the resources required for activities out-of-classrooms, being a significant barrier to the development of new teaching practices.

\section{Conclusions}

The disruption caused by the COVID-19 pandemic has created massive pressure in the education sector. Therefore, it has been necessary to imagine teaching practices to respond to this crisis. In this process, different spaces not designed for the learning process have been used, offering evidence of the fundamental role of LS in the learning experience. However, there is still a vague use of the concept. In this concern, this article distinguish three types of LS: physical, digital, and hybrid. This can be useful for researchers to establish a common ground for describing learning setups.

This work shows how LS are designed and used to support the achievement of SDGs and development of ESD competencies. The majority of the works reviewed came from before pandemic. Findings suggest that promoting SD is not the main focus of design and 
use of LS. However, sustainability has increasing importance in public debate for times to come. Therefore, the case studies reviewed give a general overview of possibilities in using different spaces to support SD.

New collaboration practices may emerge by changing classroom layouts, using devices like tablets, and using new digital platforms. The use of out-of-classroom spaces could offer experiential learning and trigger innovative teaching practices. By including the voice of users, experts, and other stakeholders in the design process of LS, flexibility and accessibility can be improved. In a dynamic phenomenon as education, further and continuous research is necessary. Therefore, a typology of LS would be helpful for its description and assessment. Additionally, we call for new frameworks that provide a broader perspective of the relation between learning and space, including long life and informal learning.

Author Contributions: Conceptualization, S.A.M.-R. and J.R.-R.; methodology, S.A.M.-R. and J.D.M.-S.; formal analysis S.A.M.-R. and A.F.G.; writing-original draft preparation, S.A.M.-R., J.R.-R. and A.F.G.; writing-review and editing, S.A.M.-R., P.Y.S.-C. and A.F.G. All authors have read and agreed to the published version of the manuscript.

Funding: This research was funded by the "Consejo Nacional de Ciencia y Tecnología (CONACYT)".

Institutional Review Board Statement: Not applicable.

Informed Consent Statement: Not applicable.

Acknowledgments: The authors of this work are especially grateful to the Faculty of Engineering of the Autonomous University of Querétaro for their support in carrying out this research.

Conflicts of Interest: The authors declare no conflict of interest.

\section{References}

1. de Giusti, A. Policy Brief: Education during COVID-19 and beyond. Rev. Iberoam. Tecnol. Educ. Educ. Tecnol. 2020, e12. [CrossRef]

2. Lehrl, S.; Linberg, A.; Niklas, F.; Kuger, S. The Home Learning Environment in the Digital Age-Associations Between SelfReported 'Analog' and 'Digital' Home Learning Environment and Children's Socio-Emotional and Academic Outcomes. Front. Psychol. 2021, 12, 1-12. [CrossRef] [PubMed]

3. Brett, M. After Coronavirus. There's No Going Back to 'Normal'. Available online: https://tribunemag.co.uk/2020/04/aftercoronavirus-theres-no-going-back-to-normal (accessed on 18 May 2021).

4. UNESCO. Education in a Post-COVID World: Nine Ideas for Public Action International Commission on the Futures of Education; UNESCO: Paris, France, 2020.

5. United Nations, Integrating the Three Dimensions of Sustainable Development. Available online: https://www.unescap.org/ sites/default/files/IntegratingthethreedimensionsofsustainabledevelopmentAframework.pdf (accessed on 30 December 2015)

6. Buckler, C.; Creech, H. UN Decade of Education for Sustainable Development (2005-2014) FINAL REPORT SUMMARY Shaping the Future We Want UN Decade of Education for Sustainable Development; United Nations Educational, Scientific and Cultural Organization: Paris, France, 2014.

7. Mulà, I.; Tilbury, D.; Ryan, A.; Mader, M.; Dlouhá, J.; Mader, C.; Benayas, J.; Dlouhý, J.; Alba, D. Catalysing Change in Higher Education for Sustainable Development: A review of professional development initiatives for university educators. Int. J. Sustain. High. Educ. 2017, 18, 798-820. [CrossRef]

8. Chattaraj, S.K. Education for Sustainable Development, Paris, France: United Nations Educational, Scientific and Cultural Organization. Int. J. Trend. Sci. Res. Dev. 2017, 2, 131-134.

9. Cleveland, B.; Fisher, K. The evaluation of physical learning environments: A critical review of the literature. Learn. Environ. Res. 2014, 17, 1-28. [CrossRef]

10. Baars, S.; Schellings, G.L.M.; Krishnamurthy, S.; Joore, J.P.; den Brok, P.J.; van Wesemael, P.J.V. A framework for exploration of relationship between the psychosocial and physical learning environment. Learn. Environ. Res. 2021, 24, 43-69. [CrossRef]

11. Guney, A.; Al, S. Effective Learning Environments in Relation to Different Learning Theories. Procedia Soc. Behav. Sci. 2012, 46, 2334-2338. [CrossRef]

12. Byers, T.; Mahat, M.; Liu, K.; Knock, A.; Imms, W. A Systematic Review of the Effects of Learning Environments on Student Learning Outcomes. Learn 2018, 1, 1-45.

13. Zitter, I.; Hoeve, A. Hybrid Learning Environments; OECD Education Working Papers No. 81; OECD Publishing: Paris, France, 2012.

14. Watson, J. On the Postcapitalist Nature of Learning Spaces. Capital. Nat. Soc. 2019, 30, 108-119 [CrossRef]

15. Agbo, F.J.; Oyelere, S.S.; Suhonen, J.; Tukiainen, M. Scientific production and thematic breakthroughs in smart learning environments: a bibliometric analysis. Smart Learn. Environ. 2021, 8, 1-25. [CrossRef] 
16. Gros, B. The design of smart educational environments. Smart Learn. Environ. 2016, 3, 1-11. [CrossRef]

17. Ifenthaler, D. Design of Learning Environments. Encyclopedia of the Sciences of Learning; Springer: Cham, Switzerland, 2012.

18. OECD. The OECD Handbook for Innovative Learning Environments; OECD Publishing: Paris, France, 2017.

19. Findler, F.; Schönherr, N.; Lozano, R.; Reider, D.; Martinuzzi, A. The impacts of higher education institutions on sustainable development: A review and conceptualization. Int. J. Sustain. High. Educ. 2019, 20, 23-38. [CrossRef]

20. Chang, B. Situated Learning-Foreign Sites as Learning Contexts. J. Comp. Int. High. Educ. 2021, 13, 5-22. [CrossRef]

21. Radcliffe, D. A Pedagogy-Space-Technology (PST) Framework for Designing and Evaluating Learning Places; Norwegian University of Science and Technology: Trondheim, Norway, 2008.

22. Space I Definition of Space by Merriam-Webster. (n.d.). Retrieved 6 September 2021. Available online: https://www.merriamwebster.com/dictionary/space (accessed on 18 May 2021).

23. Furia, P, Space and Place, A Morphological Perspective. Axiomathes 2021. [CrossRef]

24. Agnew, J.A. Space and place. In The SAGE Handbook of Geographical Knowledge; SAGE Publications: London, UK, 2011.

25. Crang, M.; Crang, P.; May, J. Virtual Geographies: Bodies, Space and Relations; Routledge: London, UK, 1999.

26. Dickenson, P.; Hall, M.T.; Courduff, J. Moving beyond the basics: The evolution of web 2.0 tools from preview to participate. Handbook of Research on the Societal Impact of Digital Media; IGI Global: Hershey, PA, USA, 2015.

27. Shi, L.; Han, L.; Yang, F.; Gao, L. The Evolution of Sustainable Development Theory: Types, Goals, and Research Prospects. Sustainability 2019, 11, 1-16. [CrossRef]

28. Pryshlakivsky, J.; Searcy, C. Sustainable Development as a Wicked Problem Sustainability: A Diffuse Paradigm. Managing and Engineering in Complex Situations; Springer: Dordrecht, The Netherlands, 2012.

29. ONU. Transforming Our World: The 2030 Agenda for Sustainable Development. 2015. Available online: https://ec.europa.eu/ environment/sustainable-development/SDGs/ (accessed on 18 May 2021).

30. Sachs, J.D.; Schmidt-Traub, G.; Mazzucato, M.; Messner, D.; Nakicenovic, N.; Rockström, J. Six Transformations to achieve the Sustainable Development Goals. Nat. Sustain. 2019, 2, 805-814. [CrossRef]

31. UNESCO-UIS. Quick Guide to Education Indicators for SDG 4; UNESCO Institute for Statistics: Montreal, QC, Canada, 2018 ; p. 48.

32. United Nations. Education for Sustainable Development Goals Learning Objectives; United Nations Educational, Scientific and Cultural Organization: Paris, France, 2017.

33. Edwards-Schachter, M. The nature and variety of innovation. Int. J. Innov. Stud. 2018, 2, 65-79. [CrossRef]

34. Hernandez, R.J.; Lancaster, I. Design, the Language of Innovation: A Review of the Design Studies Literature. She Ji J. Des. Econ. Innov. 2018, 4, 249-274. [CrossRef]

35. Norman, D.A. When You Come to a Fork in the Road, Take It: The Future of Design. She Ji 2016, 2, 343-348. [CrossRef]

36. Irwin, T. In Conversation with Terry Irwin. Research through Design and the Transition Design Perspective. Available online: https: / diposit.eina.cat/bitstream/handle/20.500.12082/847/65-173-1-PB.pdf?sequence=1\&isAllowed=y (accessed on 18 May 2021).

37. Manzini, E. Design, When Everybody Designs: An Introduction to Design for Social Innovation; MIT Press: Cambridge, MA, USA, 2015.

38. Montiel, I.; Mayoral, A.M.; Pedreño, J.N.; Maiques, S. Acoustic comfort in learning spaces: Moving towards sustainable development goals. Sustainability 2019, 11, 13. [CrossRef]

39. López-Chao, V.; Lorenzo, A.A.; Martin-Gutiérrez, J. Architectural indoor analysis: A holistic approach to understand the relation of higher education classrooms and academic performance. Sustainability 2019, 11, 6558. [CrossRef]

40. Montiel, I.; Mayoral, A.M.; Pedreño, J.N.; Maiques, S.; Santos, G.M.D. Linking sustainable development goals with thermal comfort and lighting conditions in educational environments. Educ. Sci. 2020, 10, 65. [CrossRef]

41. López-Chao, V.; Amado Lorenzo, A.; Saorín, J.L.; De La Torre-Cantero, J.; Melián-Díaz, D.; Melián-Díaz, D. Classroom indoor environment assessment through architectural analysis for the design of efficient schools. Sustainability 2020, 12, 2020. [CrossRef]

42. Errázuriz, L. Calidad estética del entorno escolar: El (f)actor invisible/Aesthetic quality of the school environment: The invisible (f)actor. Arte Individuo Soc. 2015, 27, 81-100. [CrossRef]

43. Ribalaygua Batalla, C.; García Sánchez, F. Creating a sustainable learning district by integrating different stakeholders' needs. methodology and results from the university of cantabria campus master plan. In Engaging Stakeholders in Education for Sustainable Development at University Level; Springer: Cham, Switzerland, 2016.

44. Fernández, M.J.A.d.; Villalba, M.J.S.; Olivencia, J.J.L. Perceptions of professors of educational inclusion: Diversity, cooperation and commitment. Univ. J. Educ. Res. 2020, 8, 3562-3569. [CrossRef]

45. Salinas-Navarro, D.E.; Garay-Rondero, C.L. Experiential learning in Industrial Engineering education for Digital Transformation. In Proceedings of the 2019 IEEE International Conference on Engineering, Technology and Education (TALE), Yogyakarta, Indonesia, 10-13 December 2019; pp. 1-9.

46. May, V.V.; Sullivan, C.R.; Passow, H.J.; Cushman-Roisin, B. Designing and building a tiny house to develop connections across disciplines and concepts cooperative and experiential learning work-in-progress. In Proceedings of the 2019 ASEE Annual Conference \& Exposition, Tampa, FL, USA, 15-19 June 2019.

47. O'Sullivan, N.; Hakaraia, D. The use of Maori and Pasifika knowledge within the everyday practice of commensality to enrich the learning experience. SOTL South 2018, 2, 4-17. [CrossRef]

48. Lisahunter; Rossi, T.; Tinning, R.; Flanagan, E.; Macdonald, D. Professional learning places and spaces: The staffroom as a site of beginning teacher induction and transition. Asia-Pacific J. Teach. Educ. 2011, 39, 33-46. [CrossRef] 
49. Phusavat, K.; Hidayanto, A.N.; Kess, P.; Kantola, J. Integrating Design Thinking into peer-learning community: Impacts on professional development and learning. J. Work. Learn. 2019, 31, 59-74. [CrossRef]

50. Hoinle, B.; Roose, I.; Shekhar, H. Creating transdisciplinary teaching spaces. Cooperation of universities and non-university partners to design higher education for regional sustainable transition. Sustainability 2021, 13, 3680. [CrossRef]

51. Amponsah, S. Echoing the voices of SWVIs under Covid-19 inspired online learning. Educ. Inf. Technol. 2021. doi:10.1007/s10639-021-10479-2. [CrossRef]

52. Falloon, G. Researching students across spaces and places: Capturing digital data 'on the go'. Int. J. Res. Method Educ. 2018, 41, 53-68. [CrossRef]

53. Taneri, P.O.Y.A.; Seferoglu, S.S. Technologies in Learning. Int. J. Learn. Technol. 2015, 19, 51-61.

54. Jost, F.; Newell, R.; Dale, A. CoLabS: A collaborative space for transdisciplinary work in sustainable community development. Heliyon 2021, 7, e05997. [CrossRef]

55. Gibson, D.C. Unobtrusive observation of team learning attributes in digital learning. Front. Psychol. 2018, 9, 1-5. [CrossRef] [PubMed]

56. Burbules, N.C. Spaces and places in the virtual university. In Educational Research: The Importance and Effects of Institutional Spaces; Springer: Dordrecht, The Netherlands, 2013.

57. Hu, Y.; Zhang, H. ICT in Education in China. In ICT in Education and Implications for the Belt and Road Initiative; Lecture Notes in Educational Technology; Springer: Singapore, 2020.

58. Cohen, A.; Nørgård, R.T.; Mor, Y. Hybrid learning spaces-Design, data, didactics. Br. J. Educ. Technol. 2020, 51, 1039-1044. [CrossRef]

59. Bordoloi, R.; Das, P.; Das, K. Perception towards online/blended learning at the time of Covid-19 pandemic: an academic analytics in the Indian context. Asian Assoc. Open Univ. J. 2021, 16, 41-60. [CrossRef]

60. Huang, R.; Tlili, A.; Wang, H.; Shi, Y.; Bonk, C.J.; Yang, J.; Burgos, D. Emergence of the online-merge-offline (OMO) learning wave in the post-COVID-19 era: A pilot study. Sustainability 2021, 13, 3512. [CrossRef]

61. Winter, J.; Cotton, D.; Warwick, P. The University as a Site of Socialisation for Sustainability Education. In Proceeding of Teaching Education for Sustainable Development at University Level; World Sustainability Series; Springer: Cham, Switzerland, 2016; pp. 97-108.

62. Fisher, B.; Lucas, T.; Galstyan, A. The Role of iPads in Constructing Collaborative Learning Spaces. Technol. Knowl. Learn. 2013, 18, 165-178. [CrossRef]

63. Griffiths, S.; Wong, M.S.; Kwok, C.Y.T.; Kam, R.; Lam, S.C.; Yang, L.; Yip, T.L.; Heo, J.; Chan, B.S.B.; Xiong, G.; Lu, K. Exploring bluetooth beacon use cases in teaching and learning: Increasing the sustainability of physical learning spaces. Sustainability 2019, 11, 4005. [CrossRef]

64. Kervin, L.; Comber, B.; Baroutsis, A. Sociomaterial dimensions of early literacy learning spaces: Moving through classrooms with teacher and children. In School Spaces for Student Wellbeing and Learning: Insights from Research and Practice; Springer: Singapore, 2019.

65. Lucas, M. External barriers affecting the successful implementation of mobile educational interventions. Comput. Human Behav. 2020, 107, 105509. [CrossRef]

66. Kariippanon, K.E.; Cliff, D.P.; Okely, A.D.; Parrish, A.M. The 'why' and 'how' of flexible learning spaces: A complex adaptive systems analysis. J. Educ. Chang. 2020, 21, 569-593. [CrossRef]

67. Sprod, R.; Agostinho, S.; Harper, B. What spaces? designing authentic, sustainable online learning spaces for children with diabetes. In Proceedings of the ASCILITE 2009-The Australasian Society for Computers in Learning in Tertiary Education, Auckland, New Zealand, 6-9 December 2009; pp. 1009-1012.

68. Fraser, K. The Future of Learning and Teaching in Next Generation Learning Spaces; Emerald Group Publishing Limited: Bingley, UK, 2014; Volume 12.

69. Mäkelä, T.; Helfenstein, S.; Lerkkanen, M.K.; Poikkeus, A.M. Student participation in learning environment improvement: Analysis of a co-design project in a Finnish upper secondary school. Learn. Environ. Res. 2018, 21, 19-41. [CrossRef]

70. Gugerell, K.; Zuidema, C. Gaming for the energy transition. Experimenting and learning in co-designing a serious game prototype. J. Clean. Prod. 2017, 169, 105-116. [CrossRef]

71. Carvalho, L.; Nicholson, T.; Yeoman, P.; Thibaut, P. Space matters: framing the New Zealand learning landscape. Learn. Environ. Res. 2020, 23, 307-329. [CrossRef]

72. Vilsmaier, U.; Lang, D.J. Making a difference by marking the difference: Constituting in-between spaces for sustainability learning. Curr. Opin. Environ. Sustain. 2015, 16, 51-55. [CrossRef]

73. Warwick, P. An integrated leadership model for leading education for sustainability in higher education and the vital role of students as change agents. Manag. Educ. 2016, 30, 105-111. [CrossRef]

74. el Zoghbi, M.B. Conferences as learning spaces on climate change and sustainability: Insights from university students' experiences. In Natural Resources Management: Concepts, Methodologies, Tools, and Applications; IGI Global: Hershey, PA, USA, 2016. 